\title{
As bibliotecas brasileiras em 2018: resultados da técnica de delfos
}

Maira Murrieta Costa

\begin{abstract}
Analista em C\&T do Ministério da Ciência, Tecnologia e Inovação.Mestre em Ciência da Informação (UNB)
\end{abstract}

Apresenta os principais resultados de um estudo delphi, realizado com especialistas em bibliotecas, envolvidos no oferecimento de produtos e serviços de informação. Foram avaliadas as opiniões desses especialistas quanto ao futuro das bibliotecas brasileiras em 2018. Um sistema desenvolvido em ambiente web serviu como suporte para quatro rodadas da pesquisa, que recebeu contribuições de 16 especialistas (primeira rodada) e de 14 respondentes nas três rodadas seguintes. Os resultados obtidos são apresentados em três categorias: consenso, tendência de consenso e sem consenso. Os dados revelam o impacto das tecnologias de informação e comunicação no acesso à informação, obrigando as bibliotecas a repensarem a oferta de serviços e produtos em ambientes digitais, utilizando novas tecnologias, como as colaborativas da web 2.0 e as novas formas de acesso à rede, como os tablets e smartphones. Em 2018, o atendimento remoto estará consolidado e, consequentemente, o atendimento presencial será reduzido, mas continuará sendo oferecido pelo bibliotecário.

Palavras-chave: Bibliotecas brasileiras; Futuro das bibliotecas; Estudo delphi, Técnica de delfos; Método Delphi; Tecnologia da informação.

\section{Brazilian libraries in 2018: results of the delphi technique}

It presents the main results of a Delphi study conducted with library experts, involved in providing information products and services. The opinions of these experts were evaluated on the future of libraries in Brazil in 2018. A web information system was developed to support four rounds of the survey, which received contributions from 16 experts (first round) and 14 respondents in the next 
three rounds. The study presents the results divided into three categories: consensus, consensus tendency and without consensus. The results are presented in three categories: consensus, tendency to consensus and without consensus. The data reveal the impact of information and communication technologies in information access, forcing libraries to rethink the provision of services and products in digital environments, using new technologies such as collaborative Web 2.0 and new forms of network access, such as the tablets and smartphones. In 2018 the remote service will be consolidated, thus the contact hours will be reduced but will continue to be offered by the librarian.

Keywords: Brazilian libraries; Libraries future; Delphi study; Delphi technique; Delphi method; Information technology.

Recebido em 29.07.2011 Aceito em 25.01.2012

\section{Introdução}

No epicentro da revolução tecnológica, as bibliotecas continuam a prestar serviços e disponibilizar produtos de informação, oferecendo um espaço democrático de acesso ao conhecimento, ao estudo e ao lazer. Por outro lado, os mecanismos de busca passaram a oferecer acesso a bases de dados com texto integral e, por consequência, o usuário começou a ser mais crítico quanto à necessidade de ir ou não à biblioteca, afinal, a evolução dos sistemas de informação possibilitou ao usuário o acesso à informação sem a mediação do bibliotecário. Neste contexto, surgem questionamentos sobre o futuro das bibliotecas, tais como:

a) o espaço físico da biblioteca vai diminuir?

b) as estantes e balcões de referência serão substituídos por terminais de computadores?

c) os usuários terão acesso à infraestrutura adequada para utilização de notebooks e acesso wireless à web?

d) os sistemas de informação devem propiciar a recuperação da informação por meio da linguagem natural, tags e folksonomias ou serão mantidas as tradicionais linguagens documentárias?

e) as bibliotecas devem atuar como espaços que propiciam a inclusão digital?

f) as bibliotecas utilizarão tecnologias e ferramentas da chamada web 2.0 para aprimorar os produtos e serviços de informação?

Analisando a trajetória das bibliotecas, é possível afirmar que elas continuarão a existir, mas precisarão superar desafios e evoluir continuamente (BRENDING，2011; DOUGHERTY, 2009; CUNHA，2010; 
2008; OCLC ${ }^{1}$, 2004). Com o objetivo de contribuir para a construção de um cenário futuro para as bibliotecas brasileiras, esta pesquisa apresenta os resultados da aplicação da técnica de delfos, que mobilizou especialistas com diferentes visões e graus de envolvimento com as bibliotecas. Os participantes da pesquisa responderam, em quatro rodadas distintas - ocorridas entre agosto e novembro de 2008, a um conjunto de questões e apresentaram variados graus de consenso quanto à projeção de tendências para as bibliotecas brasileiras em um horizonte limitado a dez anos (2008-2018), conforme será descrito a seguir.

\section{A biblioteca do futuro}

Há um consenso na literatura que o acervo da biblioteca tradicional é formado por documentos que utilizam o papel como suporte do registro da informação (CUNHA, 2000). Entende-se que o advento e popularização dos formatos eletrônicos de documentos e o hipertexto trouxeram à tona um dos aspectos que sempre esteve presente nas discussões sobre o futuro da biblioteca - o espaço físico. Ele irá diminuir, acabar?

A literatura indica que as pessoas continuarão precisando de um local para o estudo e para a reflexão. Assim, a Biblioteca será vista como um centro comunitário que contém ambientes propícios ao estudo pessoal, bem como para a aprendizagem colaborativa (OCLC, 2004; BREENDING, 2011).

Por outro lado, quando o assunto é acervo, há um consenso na literatura que ele gradativamente passa a estar disponível em formato digital ou eletrônico, o que influi notadamente no tamanho do espaço físico das bibliotecas. A respeito do assunto, Helen Josephine (2010) apud Cunha $\left(2010\right.$, p. 8 ) acredita que sua biblioteca ${ }^{2}$ não terá mais obras impressas dentro de uma década.

As bibliotecas universitárias brasileiras nos últimos 10 anos, têm acompanhado a diminuição da aquisição de títulos de periódicos impressos, fator que tem interferência direta no espaço físico destinado às coleções nas bibliotecas. Cabe lembrar que o movimento dos arquivos abertos, iniciado, no Brasil, em 2001, pelo IBICT, bem como o Portal de Periódicos da Coordenação de Aperfeiçoamento de Pessoal de Nível Superior (CAPES), que em 2010 fez 10 anos (CAPES, 2010), contribuíram para acelerar esse processo de diminuição da aquisição de periódicos impressos.

O acervo eletrônico e digital também traz implicações quanto ao seu processamento, disseminação e acesso. A respeito do assunto, entende-se que o livro digital (Kindle, Sony Reader, etc.), os smartphones (iPhone, BlackBerry, Galaxy S, Droid, etc.) e os tablets (iPad, Galaxy, etc.) exigirão modificações nos sistemas de gerenciamento de acervo bibliográfico. De acordo com Cunha (2010, p. 9), "o empréstimo de leitores de livros eletrônicos começou a ser introduzido na biblioteca universitária. Em

Online Computer Library Center.

Helen Josephine é chefe da Biblioteca da Escola de Engenharia da Universidade de Stanford. 
agosto de 2010, por exemplo, a North Carolina University contava com 30 iPads para empréstimo domiciliar."

A respeito dos sistemas de gerenciamento de acervo bibliográfico, Breeding (2011, p. 26) argumenta que:

[...] o modelo atual de sistemas integrados de bibliotecas surgiu numa era onde as coleções eram compostas inteiramente por materiais físicos. Esse modelo não evoluiu efetivamente de modo a absorver os formatos digitais. A partir do momento em que as coleções das bibliotecas forem, em sua maioria, compostas por materiais eletrônicos, um modelo essencialmente diferente de sistema de automação será necessário para gerenciar e prover acesso ao acervo.

Outro ponto polêmico, quando se fala do futuro das bibliotecas, diz respeito ao balcão de referência. Cunha (2000) nos lembra que muito foi falado sobre o fim do balcão de referência. O autor contextualizou o tema e ponderou que:

[...] considerando a situação precária dos mecanismos de busca existentes na www para recuperar informações relevantes, parece que o intermediário da informação ainda tem muito o que fazer [...] os bibliotecários ainda continuarão a ensinar as pessoas a fazer o melhor proveito dos recursos informacionais existentes na biblioteca, ou mesmo na Internet. (CUNHA, 2000, p.83).

Porém, em tempos de supremacia do Google, cuja missão da empresa é "organizar a informação mundial e torná-la universalmente acessível e útil" (GOOGLE, 2010), parece oportuno repensar sobre o balcão de referência, seja ele físico ou virtual.

Nesse contexto de rápidas mudanças, bibliotecários, que sempre trabalharam de forma colaborativa (redes de informação, a catalogação cooperativa, etc.), deparam-se com a possibilidade de utilizar ferramentas colaborativas típicas da web 2.0, para auxiliar no desenvolvimento de produtos e serviços de informação. A utilização dessas tecnologias e desses conceitos culminou com o surgimento do termo Library 2.0 (em português: Biblioteca 2.0).

De acordo com Mannes (2006), o termo foi criado em 2005 por Michael Casey, em seu blog - LibraryCrunch, no artigo - Service for the Next Generation Library: A Library 2.0 Perspective. Será essa a biblioteca do futuro? Quais as novidades atreladas ao termo?

Os pontos acima relatados foram objeto de discussão, análise e reflexão nesse estudo delfos, cujos resultados são apresentados a seguir. 


\subsection{A técnica de Delfos}

O Método Delphi ou Técnica de Delfos teve seu nome baseado no antigo Oráculo de Delfos, lugar sagrado na Grécia antiga, onde se anunciavam predições sobre o futuro. O método é uma técnica de previsão, projetada para conhecer com antecipação a probabilidade de eventos futuros. É uma técnica de solicitação e coleta sistemática da opinião de especialistas em um determinado assunto. A utilização do método é mais indicada quando não há dados históricos sobre o problema a ser pesquisado ou, mais especificamente, quando faltam dados quantitativos referentes ao objeto de estudo.

O método foi criado na Rand Corporation (Santa Mônica, Califórnia, EUA), em 1966, pelo pesquisador Olaf Helmer, em conjunto com Theodore Gordon e Norman Dalkey. O objetivo do método é apresentar o estudo do futuro em áreas específicas, tendo sua origem nas necessidades de pesquisa para defesa militar (HELMER, 1966; TUROFF; LINSTONE, 1975).

A literatura consultada revela que o método é uma forma de pesquisa qualitativa, que busca o consenso da opinião de um grupo de especialistas a respeito de um determinado evento futuro, por meio de rodadas interativas de questionamentos. Os pilares do método são: o anonimato, o uso de especialistas, a aplicação de rodadas interativas e o feedback controlado (HELMER, 1966; GIOVINAZZO, 2001; SAFADI, 2001).

$O$ anonimato é uma das questões menos criticadas na literatura sobre o tema. É possível considerá-la a maior vantagem do método, uma vez que, por meio dele, garante-se a igualdade de expressão de ideias. 0 uso de especialistas, por sua vez, permite que se formem conceitos, julgamentos, apreciações e opiniões confiáveis a respeito do assunto. A aplicação de rodadas interativas possibilita que as respostas sejam formatadas e novamente partilhadas. A partir dessa troca, há uma nova avaliação das respostas entre os especialistas. Consequentemente, retornos que estejam fora do contexto solicitado, são desconsiderados pelo grupo. Enquanto isso, o feedback controlado ${ }^{3}$ reduz ruídos e evita possíveis desvios de trajetórias no estudo.

A Técnica de Delfos é aplicada em diferentes áreas do conhecimento, desde as ciências exatas, da saúde e engenharias, até as humanas e sociais aplicadas. Na ciência da informação, há pesquisas que utilizam o método para identificar o futuro da área (ZINS, 2007), outras para reconhecer os padrões de bibliotecas (OCLC, 2004) e, ainda, para analisar a biblioteca como um local de estudo (LUDWIG; STARR, 2005).

\section{Metodologia do estudo}

O estudo procurou responder a seguinte pergunta: Como serão as bibliotecas brasileiras em 2018? Para tanto, desenhou-se como objetivo geral da pesquisa: identificar, a partir do consenso entre as opiniões de especialistas, como serão as bibliotecas brasileiras em 2018.

No feedback controlado, o participante recebe um resumo das discussões de todas as rodadas da pesquisa. 
Foram considerados especialistas: diretores de bibliotecas, funcionários de bibliotecas ou redes de informação, consultores ou prestadores de serviços de tecnologia da informação para bibliotecas. Dentre os especialistas selecionados para participar do estudo, havia profissionais que exerciam suas atividades em Órgãos Públicos Federais dos Poderes Executivo, Legislativo e Judiciário, empresas privadas, empresas de economia mista, organismos internacionais, universidades e empresas de consultoria. Essa diversidade teve como finalidade abranger diferentes pontos de vistas dos segmentos envolvidos com produtos, serviços e atividades de informação em bibliotecas.

A amostra da pesquisa foi formada por 25 especialistas, entretanto, só retornaram o questionário da primeira rodada 16 integrantes dessa amostra, o que gerou um percentual de participação de $64 \%$ na primeira rodada.

A segunda rodada iniciou-se apenas com os 16 integrantes que haviam participado da primeira rodada. O retorno de questionários da segunda rodada teve um índice de $90 \%$. Consequentemente, a terceira rodada teve sua amostra composta por 14 especialistas e todos eles responderam as questões da terceira e quarta rodada, o que configurou um índice de participação de $100 \%$ nessas rodadas. A Tabela 1 sintetiza as etapas da pesquisa, a amostra e o índice de participação em cada rodada do painel

Tabela 1 - Amostra do estudo de acordo com a rodada

\begin{tabular}{l|c|c|c}
\hline Etapas da Pesquisa & Amostra & Respondida por & Índice de Participação \\
\hline $1^{\circ}$ Rodada & 25 especialistas & 16 especialistas & $64 \%$ \\
\hline $2^{\circ}$ Rodada & 16 especialistas & 14 especialistas & $90 \%$ \\
\hline $3^{\circ}$ Rodada & 14 especialistas & 14 especialistas & $100 \%$ \\
\hline $4^{\circ}$ Rodada & 14 especialistas & 14 especialistas & $100 \%$
\end{tabular}

Fonte: OLIVEIRA; COSTA; WILLE (2008).

\subsection{O sistema de coleta de dados}

A coleta de dados, bem como o controle de todo o estudo, foram realizados em ambiente $w e b$. Para tanto, foi desenvolvido um sistema em linguagem PHP. O banco de dados foi desenvolvido em um sistema gerenciador de banco de dados relacional (SGBD-R), uma vez que este viabiliza a implementação de regras de integridade diretamente pelo sistema, proporcionando maior flexibilidade para alterações na estrutura dos dados. O SGBD selecionado foi o MySQL, por ser padrão de mercado, ter código fonte aberto e ser compatível com a maioria dos sistemas operacionais.

Os requisitos técnicos do sistema foram: identificação do nome do participante e sua instituição; gerenciamento das rodadas do painel Delphi e o gerenciamento da participação nas rodadas, inclusive impedindo a alteração dos dados anteriormente preenchidos. Os requisitos de segurança, por sua vez, foram: registro da operação, a data e a hora do acesso dos usuários; criação de Módulo de Administração do sistema com acesso apenas aos coordenadores da pesquisa; e criação de URL 
randômica para geração de questionários dinâmicos, para garantir o anonimato (OLIVEIRA; COSTA; WILLE, 2008).

A elaboração do banco de dados foi a etapa mais delicada do sistema, pois a primeira rodada do estudo foi composta por perguntas abertas, conforme será descrito a seguir, impossibilitando o desenvolvimento prévio de um Modelo de Entidade Relacionamento (MER). Apenas após a análise dos dados desta primeira rodada, o banco de dados foi ajustado para administrar os dados de todo o painel Delphi. Acrescentaram-se quatro tabelas no MER, a saber: categoria, subcategoria, respostas mais votadas, grupo mais votado. As tabelas de categoria e subcategoria foram carregadas com dados, viabilizando o início da segunda rodada. Os resultados obtidos na terceira e quarta rodadas não provocaram mudanças no modelo previamente definido.

Com a automação dos processos do estudo, obteve-se os seguintes benefícios: significativa agilidade no preenchimento e análise dos dados; facilidade e confiança no uso por parte dos especialistas; e criação de uma forma única e homogênea de acesso aos dados coletados.

\subsection{As quatro rodadas de coleta de dados}

O estudo teve quatro rodadas distintas. A primeira consistiu em um questionário estruturado com três perguntas abertas, divididas em três categorias: espaço físico, atendimento ao usuário e serviços/produtos de informação, conforme demonstra o Quadro 1.

Quadro 1 - Perguntas do questionário da primeira rodada

\begin{tabular}{|l|l|}
\hline \multicolumn{1}{|c|}{ Pergunta } & \multicolumn{1}{c|}{ Itens explicativos da pergunta } \\
\hline $\begin{array}{l}\text { 1. Na sua opinião, como será o espaço } \\
\text { físico* das bibliotecas daqui há 10 anos? }\end{array}$ & $\begin{array}{l}\text { * Para fins deste estudo, entende-se como espaço físico: a } \\
\text { estrutura predial das bibliotecas, suas divisões, seus } \\
\text { mobiliários e recursos físicos disponíveis. }\end{array}$ \\
\hline $\begin{array}{l}\text { 2. De acordo com a sua resposta à pergunta } \\
\text { 1, como se dará o atendimento ao usuário em } \\
\text { função deste espaço? }\end{array}$ & \\
\hline $\begin{array}{l}\text { 3. Quais os produtos*/serviços** de } \\
\text { informação que deverão ser mantidos, } \\
\text { aprimorados e/ou criados para melhor } \\
\text { atender o usuário nesse contexto? }\end{array}$ & $\begin{array}{l}\text { * Por produto de informação entenda um conjunto de } \\
\text { serviços tangíveis tais como: bibliografias, catálogos, } \\
\text { tesauros, bases de dados dentre outros. } \\
\text { ** Por serviço de informação entenda atividades voltadas } \\
\text { para o fornecimento de informaçóes aos usuários, tais } \\
\text { como: disseminação seletiva da informação (DSI), } \\
\text { atendimento ao usuário dentre outros. }\end{array}$ \\
\hline
\end{tabular}

Fonte: OLIVEIRA; COSTA; WILLE (2008).

$\mathrm{Na}$ segunda rodada, os participantes receberam resumos da discussão da primeira rodada (feedback controlado), da qual se extraíram, a partir de uma análise qualitativa, subcategorias dentro de cada categoria definida no questionário da primeira rodada (espaço físico, atendimento ao usuário e serviços/produtos de informação).

A finalidade do feedback controlado consistiu em dar ao participante a oportunidade de confirmar ou não as subcategorias extraídas de sua resposta qualitativa, bem como refletir sobre as subcategorias apresentadas pelos outros participantes. Merece destaque que foi dada atenção especial na manutenção do anonimato nesse processo. Tal estratégia teve como finalidade reduzir os ruídos, evitando possíveis desvios de trajetória no estudo. 
A terceira rodada foi composta de duas perguntas fechadas. A primeira apresentou as 23 subcategorias mais votadas na rodada anterior e pediu aos participantes que selecionassem as 10 subcategorias que fossem, na sua opinião, mais significativas, conforme demonstra o Quadro 2.

Quadro 2 - Subcategorias mais votadas na terceira rodada.

\begin{tabular}{|c|l|c|}
\hline \multicolumn{2}{|c|}{ Subcategorias } & $\begin{array}{c}\text { Quantidade de } \\
\text { Votos }\end{array}$ \\
\hline $\mathbf{1}$ & Atendimento Remoto/Virtual & 26 \\
\hline $\mathbf{2}$ & Informação On-line & 14 \\
\hline $\mathbf{3}$ & Acessibilidade & 12 \\
\hline $\mathbf{4}$ & Agilidade & 12 \\
\hline $\mathbf{5}$ & Wireless & 11 \\
\hline $\mathbf{6}$ & Autonomia/independência do usuário & 11 \\
\hline $\mathbf{7}$ & OPAC Texto Integral & 11 \\
\hline $\mathbf{8}$ & Interoperabilidade & 10 \\
\hline $\mathbf{9}$ & Sistemas Inteligentes & 10 \\
\hline $\mathbf{1 0}$ & Equipamentos de TI & 10 \\
\hline $\mathbf{1 1}$ & Espaço Reduzido & 9 \\
\hline $\mathbf{1 2}$ & Centrais de Atendimento & 9 \\
\hline $\mathbf{1 3}$ & Web semântica & 9 \\
\hline $\mathbf{1 4}$ & Inclusão Digital & 9 \\
\hline $\mathbf{1 5}$ & Taxonomia/Ontologia no motor de busca & 8 \\
\hline $\mathbf{1 6}$ & Tutoriais & 8 \\
\hline $\mathbf{1 7}$ & Serviços e produtos para pessoas deficientes & 8 \\
\hline $\mathbf{1 8}$ & Estrutura adequada para notebooks & 8 \\
\hline $\mathbf{1 9}$ & Biblioteca 2.0 & 8 \\
\hline $\mathbf{2 0}$ & Autoserviço & 8 \\
\hline $\mathbf{2 1}$ & Treinamento do usuário & 8 \\
\hline $\mathbf{2 2}$ & Interface única de acesso à informação & 7 \\
\hline $\mathbf{2 3}$ & Mediação do bibliotecário & 6 \\
\hline
\end{tabular}

Fonte: OLIVEIRA; COSTA; WILLE (2008).

A quarta e última rodada foi composta por 14 afirmativas apresentadas em escala tipo Likert, conforme será discutido no tópico referente à análise dos dados.

\subsection{Tratamento estatístico dos dados}

O tratamento estatístico consistiu na análise descritiva dos dados, a partir da obtenção das respostas dos questionários da quarta rodada. Em seguida, foi realizada a análise da distribuição das frequências das variáveis, com a finalidade de verificar a pontuação obtida, ou seja, o nível de concordância dos respondentes por questão.

Foi utilizada a escala likert de 7 pontos ( 1 a 7), na qual o número 1 representa a posição de não concordância máxima, e o número "7" da escala representando maior o nível de concordância. Considerou-se como consenso uma porcentagem igual ou maior que $85 \%$ na soma das indicações nos números 6 e 7 da escala e a média das respostas com valor superior a 6 . As demais afirmativas, que não corresponderam a esse critério, foram inseridas na categoria tendência de consenso, além disso a média das respostas precisou ter um valor entre 4 e 6 . Nos casos em que o peso percentual pulverizou-se na escala ou o peso das respostas concentrou-se nos números 3, 2 e 1 da escala, bem como nos casos em que a média foi inferior a 4, a afirmativa foi inserida na categoria "não há consenso" - conforme demonstra o Quadro 3. 
Quadro 3 - Escala de análise das afirmativas quanto ao consenso.

\begin{tabular}{|c|l|l|}
\hline Situação & \multicolumn{1}{c|}{ Descrição } \\
\hline Consenso & $\begin{array}{l}\text { Porcentagem igual ou maior que 85\% } \\
\text { na soma das indicações nos números } \\
6 \text { e 7 da escala. }\end{array}$ & $\begin{array}{l}\text { Valor superior a 6 } \\
(\mathrm{V}>6)\end{array}$ \\
\hline $\begin{array}{c}\text { Tendência de } \\
\text { consenso }\end{array}$ & $\begin{array}{l}\text { Demais afirmativas que não } \\
\text { corresponderam ao critério de } \\
\text { consenso. }\end{array}$ & $\begin{array}{l}\text { Valor entre 4 e 6. } \\
(\mathrm{V}>4 \text { e }<6)\end{array}$ \\
\hline $\begin{array}{c}\text { Não há } \\
\text { consenso }\end{array}$ & $\begin{array}{l}\text { Casos em que o peso percentual } \\
\text { pulverizou-se na escala ou o peso das } \\
\text { respostas concentrou-se nos números } \\
3,2 \text { e 1 da escala Likert. }\end{array}$ & $\begin{array}{l}\text { Valor inferior a } 4 \\
(\mathrm{~V}<4)\end{array}$ \\
\hline
\end{tabular}

Fonte: Adaptado de OLIVEIRA; COSTA; WILLE (2008).

Para a obtenção dos percentuais por categoria, foi aplicada a análise das frequências relativas. Por meio da análise das frequências acumuladas, os resultados acumulados foram verificados em cada subcategoria, da mais baixa a mais alta.

Além do exposto, foram calculadas: a média aritmética da distribuição, moda para definição da subcategoria que ocorre com maior frequência e por fim, a mediana que divide a distribuição pela metade.

Com o objetivo de verificar onde estão espalhadas as pontuações ou valores obtidos, como medida de variabilidade, foi aplicado o desviopadrão, para verificar o quanto cada conjunto de pontuações foi desviado da média.

Para a medida de confiabilidade e consistência interna, foi aplicado o coeficiente de alfa de Cronbach padronizado. Todos esses cálculos foram realizados com o auxílio do Statistical Package for the Social Sciences (SPSS) versão 15.0. e tiveram como objetivo verificar o consenso ou não consenso em cada afirmativa apresentada na última rodada. Assim, quanto mais para a direita o pico da curva estivesse no gráfico da assimetria e curtose, mais tendendo ao consenso estava a variável (no caso, afirmativa apresentada).

\section{Análise dos dados}

Os dados serão apresentados de acordo com o grau de consenso das afirmativas. Assim, serão apresentadas primeiramente as afirmativas que obtiveram consenso, seguida das que obtiveram tendência de consenso. Por último, serão discutidas as afirmativas que não alcançaram consenso.

No que diz respeito à análise dos dados, cabe relembrar que cada subcategoria, relacionada no Quadro 2, foi levantada pelos especialistas e não a partir de itens coletados na literatura nacional e internacional. A

ssim, as afirmativas da quarta rodada foram desenvolvidas com fundamento nas categorias indicadas na terceira rodada da pesquisa.

Interessante observar que a análise qualitativa das respostas da primeira rodada revelaram uma preocupação com o espaço físico da biblioteca (redução/ampliação do espaço físico). Porém, a partir da segunda rodada, nenhuma das subcategorias, desenvolvidas para analisar o tema (espaço reduzido, centrais de atendimento, mediação do 
bibliotecário), ficou entre as mais votadas, conforme demonstrado no Quadro 3.

\subsection{Afirmativas que obtiveram consenso entre os especialistas}

Constatou-se que sete (Afirmativas 1, 3, 5, 7, 11, 12 e 14) das quatorze afirmativas alcançaram o consenso entre os especialistas, conforme demonstra o Gráfico 1

Gráfico 1 - Afirmativas que alcançaram o consenso

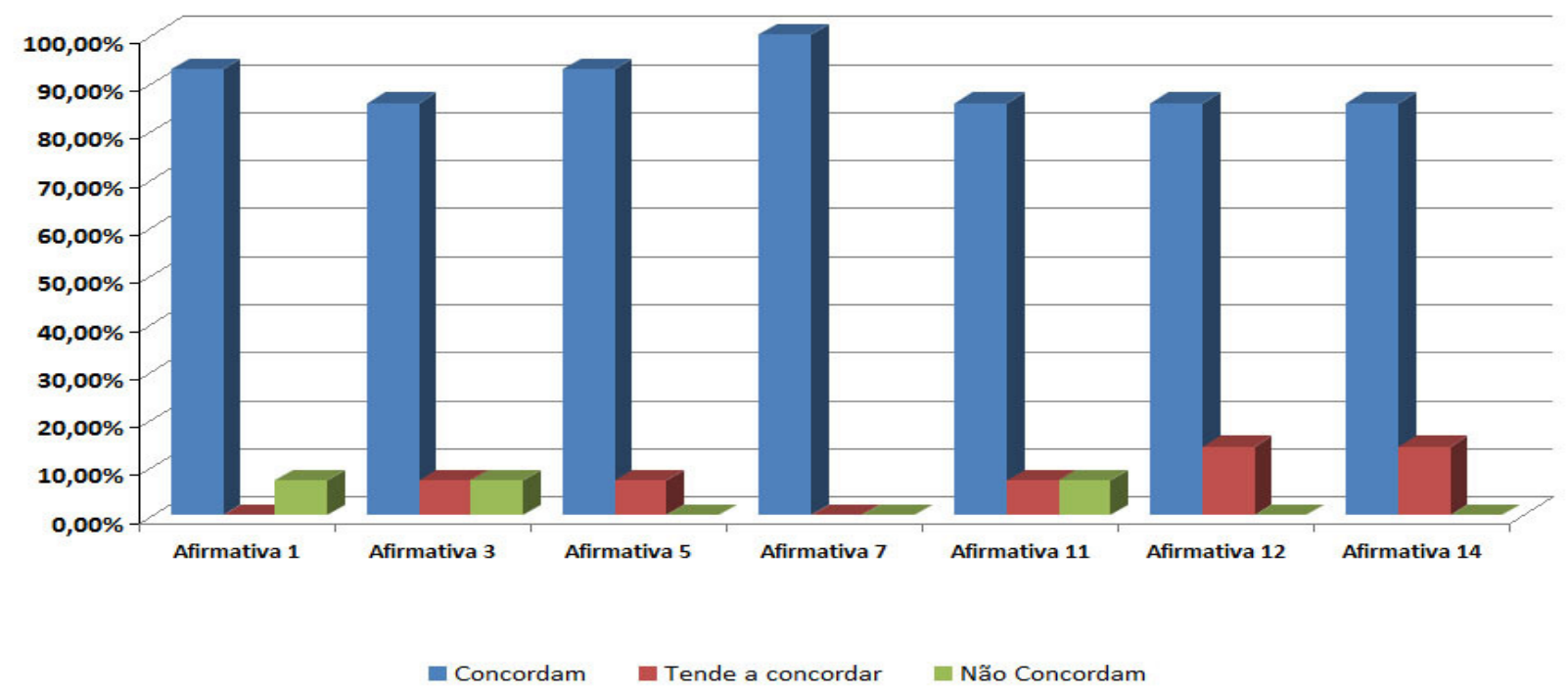

Fonte: Dados da pesquisa.

A Afirmativa 1 dizia - "As bibliotecas brasileiras, em 2018, oferecerão aos usuários acesso remoto, diminuindo (mas não eliminando) o atendimento presencial". Esta afirmativa obteve um consenso de $\mathbf{9 2 , 8 \%}$ das respostas escolhidas entre as opções 6 e 7 da escala likert, o que resultou em uma média $\mathbf{6 , 5 0}$.

Já a Afirmativa 3 - "Em 2018, serviços de informação serão projetados e concebidos, pelas bibliotecas brasileiras, para ir ao encontro do usuário, suprimindo a necessidade de deslocamento à biblioteca física". Esta afirmativa obteve um consenso de $\mathbf{8 5 , 7 \%}$ entre os especialistas, resultado da soma das opções 6 e 7 da escala likert, o que resultou em uma média de 6,07.

O consenso da Afirmativa 1 e da Afirmativa 3 não apresentam novidades, apenas confirmam estudos já publicados sobre o tema, tais como o de Cunha (2000) e Bell (2007) apud Dagger (2008).

A Afirmativa 5 dizia - "Mesmo com a consolidação do atendimento remoto, a figura do bibliotecário, em 2018, continuará a existir para atender o usuário." Essa afirmativa obteve um consenso de $\mathbf{9 2 , 9 \%}$ dos especialistas, resultando em uma média igual a 6,71. Essa afirmativa representa o fato de que antes da Internet, os bibliotecários tinham um 
total controle sobre as ferramentas de busca. A simplificação dos mecanismos de busca, como o Google, facilita o acesso à informação sem mediadores, obrigando os bibliotecários a refletirem sobre um novo modelo de atendimento ao usuário.

Nesse aspecto, cabe citar a palestra proferida por Steven Bell, em 2007, no Simpósio sobre Sistemas de Bibliotecas da Universidade de Columbia, na qual ele comentou que o balcão de referência seria eliminado das bibliotecas em 2012. A colocação de Bell causou grande impacto em um primeiro momento, mas o próprio Bell, ao longo de sua palestra, reforçou que o atendimento ao usuário será mais importante do que nunca. O momento exige que o bibliotecário proponha um novo modelo de atendimento, onde possa atender demandas durante 24 horas. (DAGGER, 2008).

A Afirmativa 7 - "Para estreitar o relacionamento com consumidores de informação (usuários), as bibliotecas brasileiras, incorporarão, em 2018, as novas tecnologias de informação advindas com a web 2.0". Essa afirmativa foi a única que obteve um consenso de $\mathbf{1 0 0 \%}$ dos especialistas e obteve uma média igual a 6,79. Esse resultado representa o pensamento homogêneo dos especialistas quanto ao uso de novas tecnologias de informação nas bibliotecas.

A biblioteca 2.0 extrai as ideias e os conceitos da web 2.0 e os aplica dentro do ambiente de bibliotecas, estimulando a utilização das ferramentas colaborativas, tais como os blogs, twitter, wikis, social bookmarking, instant messaging e podcasting (CUNHA, 2010; COSTA, 2009).

A literatura internacional já indica a utilização de wikis e social bookmarking para o desenvolvimento de guias de literatura na web (FARKAS, 2007a; 2007b; FARKAS 2008; RETHLEFSEN, 2007), o uso do RSS para manter o usuário informado sobre os novos itens da coleção, novos serviços e novos conteúdos nas bases de dados (MANNES, 2006), bem como o uso do instant messaging, para proporcionar serviços de referência por Chat (MANNES, 2006).

Apesar do consenso dos especialistas a respeito do tema, bem como apesar da literatura internacional já relatar aplicações de uso dessas ferramentas em bibliotecas, Dutra (2010), em sua pesquisa, identificou que apenas 85 bibliotecas brasileiras utilizavam o twitter em maio de 2010. A autora conclui que:

[...] as contas do Twitter são utilizadas pelas bibliotecas principalmente para divulgação das informações com links, em detrimento de atividades de interação com o usuário [...] pode-se concluir que o uso do Twitter pelas bibliotecas ainda 
se faz tímido, mas evidencia-se uma evolução (DUTRA, 2010, p. 41).

Costa (2011), em pesquisa que avaliou o potencial do social bookmarking para o desenvolvimento de guias de literatura na web, identificou que $52 \%$ dos entrevistados ${ }^{4}$ declararam não conhecer tais plataformas, enquanto $48 \%$ declararam que as conheciam, mas não as usavam. Durante o período da pesquisa, a autora não identificou nenhuma biblioteca brasileira que utilizasse as plataformas de social bookmarking com tal finalidade e observa que a barreira linguística pode estar inibindo o uso dessas plataformas por pesquisadores e bibliotecários brasileiros.

A Afirmativa 11 dizia - "Em 2018, a integração dos sistemas de gerenciamento de acervo de bibliotecas se voltará para a integração com os demais sistemas organizacionais". Essa afirmativa obteve um consenso de $\mathbf{8 5 , 7 \%}$ entre os especialistas e média igual a 3,36.

O resultado da Afirmativa 11 vai de encontro a previsões anteriores da OCLC sobre o tema - "há uma crescente ênfase na integração entre sistemas de suporte ao aprendizado, à pesquisa e a administração [...] depois de um longo domínio do sistema integrado de bibliotecas, estamos vivendo uma transição para um ambiente com mais sistemas" (OCLC, 2004, p. 14-15). Por outro lado, há que se ressaltar que nenhum dos participantes fez comentários a respeito do impacto dos tablets e smartphones no sistema de gerenciamento de acervo das bibliotecas. Ou seja, apesar de terem refletido sobre a interação deste sistema com os demais da organização, os especialistas consultados não se alertaram sobre a necessidade interna da biblioteca de prover mudanças rápidas no sistema de gerenciamento de seu acervo.

A Afirmativa 12, por sua vez, dizia - "Em 2018, as bases de dados de texto integral estarão amplamente consolidadas, diferenciando-se por serviços adicionais". Essa afirmativa obteve um consenso de $\mathbf{8 5 , 7 \%}$ entre os especialistas, o que resultou em uma média igual a 6,36.

Conforme já discutido neste artigo, o movimento dos arquivos abertos e o Portal de Periódicos da Capes aceleraram o processo de diminuição da aquisição de periódicos impressos, uma vez que os fascículos estão agora disponíveis em repositórios digitais. Assim, o consenso sobre Afirmativa 12 não representa grande novidade para as bibliotecas brasileiras. As bases de dados de texto integral têm galgado espaço aos poucos, além disso, projetos de digitalização do acervo de grandes bibliotecas culminam com a consolidação do acesso às bases de dados de texto integral.

A última afirmativa que obteve consenso foi a Afirmativa 14 que dizia - "Em 2014, a web-semântica terá pressionado os bibliotecários a reverem suas atividades profissionais para absorção de novas tarefas". Essa afirmativa obteve um consenso de $\mathbf{8 5 , 7 \%}$ entre os especialistas e uma média igual a 6,36.

A amostra foi composta por alunos de pós-graduação em ciência da informação na UnB. 
A respeito do assunto, percebe-se que, apesar da web semântica estar em seus estágios iniciais, o consenso sobre a Afirmativa 14 também não representa novidade, pois essa nova área pretende que "algumas atividades possam ser executadas não só por usuários, mas também por programas [...] que ajudariam a automatizar tarefas mais complexas." (CAMPOS; CAMPOS; CAMPOS, 2006, p. 56).

Foi observado que todas as afirmativas que constam no Gráfico 1, referem-se ao impacto da tecnologia da informação e comunicação no ambiente de bibliotecas e seus reflexos no atendimento remoto aos usuários.

\subsection{Afirmativas com tendência de consenso entre os especialistas}

As Afirmativas 2, 4, 9, 10 e 13 apresentaram apenas uma tendência de consenso, conforme demonstra o Gráfico 2 .

Gráfico 2 - Afirmativas com tendência ao consenso

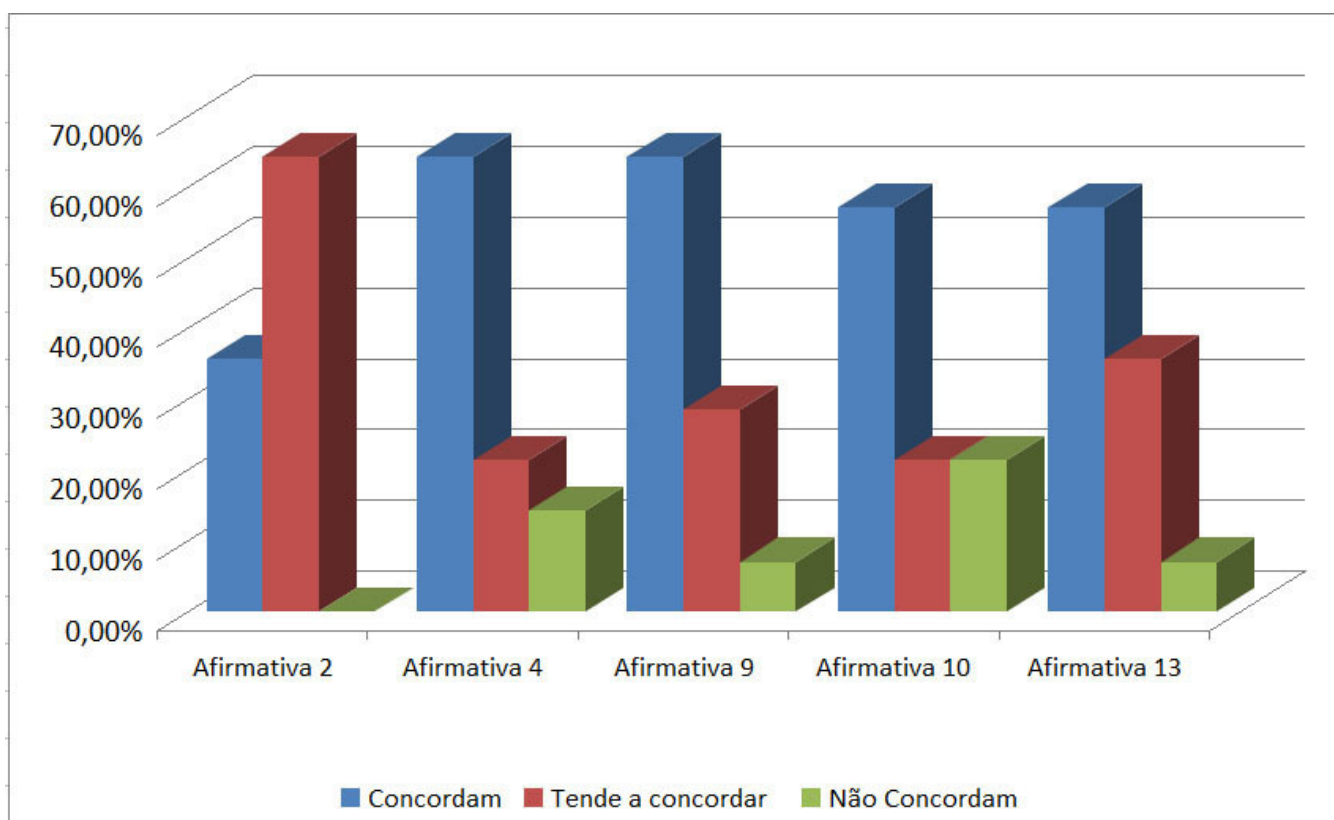

Fonte: Dados da pesquisa.

A Afirmativa 2 dizia - "As bibliotecas brasileiras, em 2018, terão a infraestrutura física e tecnológica de acordo com os critérios de acessibilidade". Não se obteve consenso quanto à afirmativa. Mas observou-se uma tendência de consenso, com um percentual de 64,3\%, demonstrada através da escolha das opções 6 e 7 da escala likert, o que resultou em uma média igual a 5,93.

Apesar da Lei 10.098, de 19 de novembro de 2000 (BRASIL, 2000), que estabelece normas gerais e critérios básicos para a promoção da acessibilidade das pessoas portadoras de deficiência ou com mobilidade reduzida, estar em vigor no Brasil há 11 anos, é interessante observar que 
a Afirmativa 2 obteve apenas tendência de consenso, o que pode demonstrar desconhecimento da Legislação sobre o tema abordado, ou pode refletir as dificuldades financeiras que as bibliotecas enfrentam, 0 que consequentemente inviabiliza as alterações necessárias para atender os deficientes físicos ou pessoas com mobilidade reduzida. A mesma observação para vale para o atendimento ao deficiente visual na internet. Afinal, os sites precisam ser desenvolvidos observando os critérios da W3C, em especial as tags de acessibilidade, viabilizando, assim, o acesso a esse público.

Já a Afirmativa 4 - "As bibliotecas brasileiras, em 2018, oferecerão o atendimento remoto por meio de dispositivos móveis, além da internet". Observou-se uma tendência de consenso, pois a soma os valores 6 e 7 da escala representaram $64,3 \%$ do total da amostra, o que resultou em uma média igual a $\mathbf{5 , 7 9}$.

É pertinente cruzar os dados da Afirmativa 3 e Afirmativa 4. Pois, na Afirmativa 3, houve um consenso de $85,7 \%$ dos especialistas de que os serviços de informação serão projetados para ir ao encontro do usuário. $\mathrm{E}$ a Afirmativa 4 propõe que a biblioteca ofereça serviços por meio de dispositivos móveis além da internet, portanto, apresenta uma alternativa para ir ao encontro do usuário.

É salutar que o bibliotecário reflita sobre esse tema, pois estamos vivenciando uma era de acesso à informação digital (bibliotecas digitais, repositórios, portais, etc.) na qual se faz absolutamente necessário que o bibliotecário vá de encontro ao usuário. Há que se considerar que a Geração Y é uma geração crédula na supremacia da web para localizar qualquer tipo de informação. E essa geração é a usaria potencial dos serviços de bibliotecas universitárias e especializadas. Por conta do comportamento dessa nova geração de usuários potenciais, parece prudente que as bibliotecas desenvolvam capacidades para atender seu usuário por meio dos novos dispositivos móveis de acesso à internet, tais como os tablets e smartphones.

A respeito do assunto, Cunha e Pessoa (2007, p. 78) argumentam que "no Brasil, não existem serviços de referência virtuais que utilizem as tecnologias mais modernas de comunicação disponíveis, exceto o correio eletrônico, é claro". Nesse cenário, a tendência de consenso dos especialistas para a Afirmativa 4 revela que muito ainda tem que ser feito para o aprimoramento do atendimento remoto ao usuário, seja por meio de dispositivos móveis ou a própria internet.

A Afirmativa 9, por sua vez, dizia - "Em 2018, as redes sem fio serão um serviço obrigatório ao usuário, oferecido pelas bibliotecas brasileiras". Há uma tendência ao consenso, afinal os valores 6 e 7 da escala apresentaram um total de $\mathbf{6 4 , 3 \%}$ das respostas coletadas e uma média igual a 5,79.

Há que se ressaltar que a tecnologia wi-fi veio para ficar. É uma tecnologia de grande aceitação por parte de seus usuários em ambientes públicos como aeroportos, shoppings centers, restaurantes e salas de 
espera de consultórios médicos. É necessário refletir que a biblioteca também é um espaço público, mas, acima de tudo, é um espaço de acesso à informação, portanto, o uso da tecnologia wi-fi torna-se pertinente ao conjunto de serviços e facilidades a serem oferecidas pelas bibliotecas em um futuro próximo, principalmente ao se levar em consideração a penetração dos smartphones e tablets no mercado de informação. A respeito do assunto, a OCLC já havia detectado "wi-fi é uma tecnologia que conquistou o coração do consumidor de informação e está ocupando as mesas de café de todo o mundo" (OCLC, 2004, p. 10).

A Afirmativa 10 dizia - "As bibliotecas brasileiras, em 2018, oferecerão predominantemente acesso a bases de dados (textual, numérica, visual etc.) de conteúdo integral". Observou-se uma Tendência de Consenso entre os especialistas. Merece destaque que apesar da soma das opções 6 e 7 na escala likert representaram apenas $\mathbf{5 7 , 2} \%$ das respostas, indicando inicialmente uma ausência de consenso, a média das respostas foi de $\mathbf{5 , 4 3}$, portanto, evidenciando forte tendência ao consenso por estar mais próximo do nível 6 da escala

Aqui vale refletir que a Afirmativa 12 obteve consenso, mas a Afirmativa 10 - que trata do acesso às bases de dados em texto integral pelas bibliotecas brasileiras - obteve apenas uma tendência de consenso. A partir dos dados, entende-se que o acesso às bases de dados de texto integral é um fato. A questão é se as bibliotecas brasileiras vão oferecer esse acesso. Infere-se que a afirmativa obteve apenas uma tendência de consenso em função dos altos custos de assinatura dessas bases de dados.

Já a Afirmativa 13 - "Em 2018, os sistemas de busca de bibliotecas se apoiarão em sistemas especialistas com alta capacidade de aprendizagem". Foi observada uma Tendência de Consenso entre os especialistas. Apesar da soma dos valores 6 e 7 da escala likert representam um valor de apenas $\mathbf{5 7 , 2 \%}$, indicando inicialmente uma ausência de consenso, a média das respostas foi de $\mathbf{5 , 7 9}$, portanto, evidenciando forte tendência ao consenso, por estar muita próxima do nível 6 da escala likert.

É natural que essa afirmativa tenha obtido apenas uma tendência de consenso. Na opinião de Campos, Campos e Campos (2006, p. 56), "a web semântica encontra-se nos seus primórdios e, por isso mesmo, é ainda encarada com ceticismo por muitos". Para os autores "há evidências de que sua consolidação depende de tempo e do amadurecimento das tecnologias utilizadas" (CAMPOS, CAMPOS, CAMPOS, 2006, p. 71).

\subsection{Afirmativas com ausência de consenso}

As afirmativas 6 e 8 não alcançaram consenso, conforme demonstra o Gráfico 3.

Gráfico 3 - Afirmativas que não obtiveram consenso 


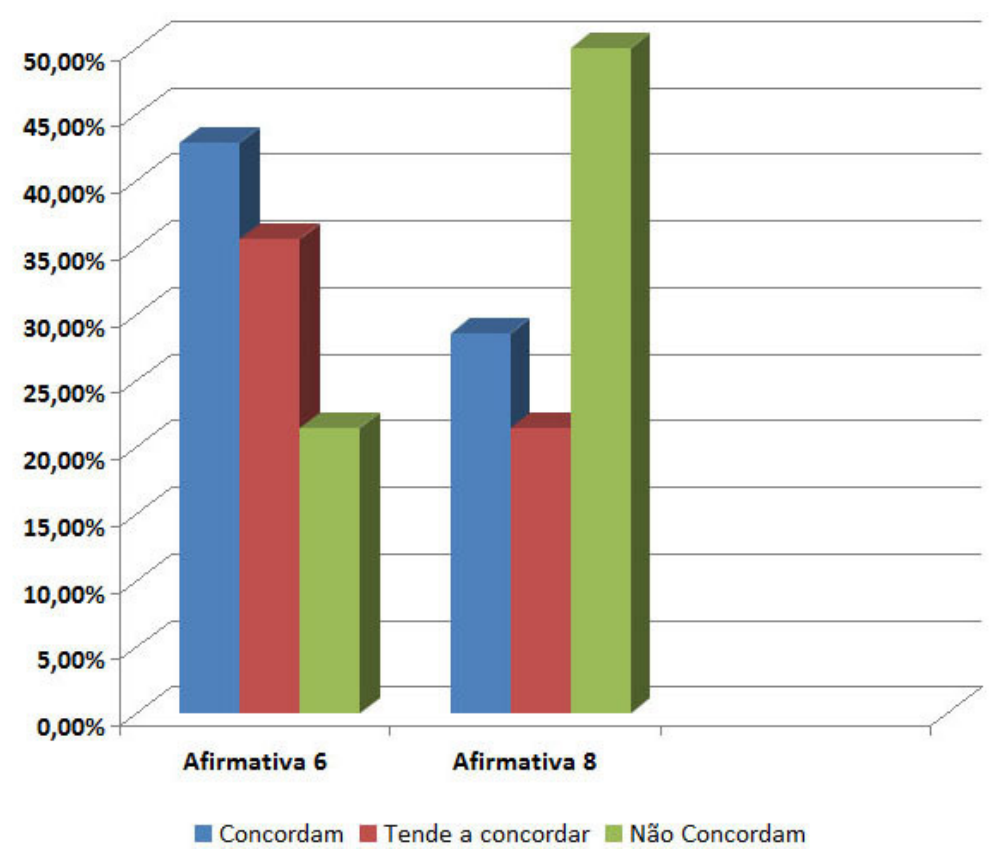

Fonte: Dados da pesquisa.

A Afirmativa 6 dizia - "Tecnologias de realidade virtual serão utilizadas pelas bibliotecas brasileiras, em 2018, para propiciar atendimento remoto/virtual aos consumidores de informação (usuários)". Não houve consenso entre os especialistas, pois a distribuição das respostas demonstra que as opiniões estão bem distribuídas entre as frequências e, como resultado, obteve-se uma média igual a 4,93.

Apesar do avanço das tecnologias de informação e comunicação no Brasil, esse estudo não obteve consenso sobre a utilização de tecnologias de realidade virtual por bibliotecas. Há que se ressaltar que no Second Life, já existem balcões de referência virtual, a exemplo cita-se o Info Island International e o Mark and Emily Turner Memorial Library (Maine), dentre outros. Porém, há que se ressaltar que no Brasil, apesar de em 2010, 73,9 milhões de brasileiros acessarem a internet ${ }^{5}, 48 \%$ das conexões variam entre $512 \mathrm{Kbps}$ e $2 \mathrm{Mbps}$ e apenas $5,5 \%$ dos usuários residências contratam velocidades superiores a $8 \mathrm{Mbps}$; e $7 \%$ ainda usam conexão discada, o que dificulta e em alguns caso inviabiliza a utilização de tecnologias de realidade virtual.

Já a Afirmativa 8 dizia - "Em 2018, a função das centrais de atendimento (balcão de referência) ao usuário estará comprometida, pois o usuário vai atuar de forma cada vez mais autônoma (autoserviço)". Novamente não houve consenso entre os especialistas. Vale destacar que a opção 3 da escala likert, que obteve $35,7 \%$ das respostas. Essa opção somada ao valor 1 da escala representa um total acumulado de $50 \%$, portanto, demonstrando o não consenso de metade dos participantes, o que resultou em uma média igual a 3,86.

Os dados apontam (ver Afirmativas 3, 4 e 7 ) para um serviço de referência virtual, corroborando com a opinião de Cunha (2008), que

$5 \quad$ Dados fornecidos pelo Ibope Nielsen OnLine. 
alertou - "referência em todos os lugares: pessoalmente, e-mail, chat etc." Percebe-se que o autoserviço está cada vez mais presente em atividades mecânicas, como, por exemplo, o empréstimo/devolução com o apoio da tecnologia RFID. Porém, as atividades intelectuais dos bibliotecários no apoio à recuperação da informação, continuarão a ser importantes.

\section{Conclusão}

Prever o futuro não é tarefa fácil e livre de conflitos. Os dados da pesquisa revelaram que a biblioteca física em 2018 continuará a existir, o atendimento remoto estará consolidado e, consequentemente, o atendimento presencial será reduzido, mas continuará sendo oferecido pelo bibliotecário.

A única afirmativa que obteve o consenso de $100 \%$ dos especialistas referia-se à utilização, pelas bibliotecas brasileiras, das tecnologias da web 2.0 para estreitar seu relacionamento com o usuário. Apesar do consenso entre os especialistas, Costa (2009) observou que:

[...] as bibliotecas brasileiras ainda não despertaram para os benefícios desta tecnologia na oferta de produtos e serviços de informação. Fator que impõe, aos profissionais da informação, desafios quanto ao processo de utilização de ferramentas colaborativas (COSTA, 2009, p. 11).

Sobre o uso de tecnologias, percebe-se que, no Brasil, a utilização de redes sociais e de tecnologias de Instant Messaging tem uma conotação negativa, implicando na dispersão das atividades profissionais. Os órgãos públicos federais, por exemplo, tendem a bloquear o acesso aos sites de redes sociais como twitter, blogs e programas como MSN, Gtalk, Skype, etc., e, dessa forma, inviabilizam o uso pela biblioteca. Em contrapartida, bibliotecas americanas demonstram uma grande utilização dessas ferramentas para intensificar o relacionamento com o usuário.

Cunha (2000, p. 5) acreditava que em 2010 "a quase totalidade, se não a totalidade das bibliotecas universitárias brasileiras estar[iam] automatizadas, e muitas delas ser[iam] bibliotecas completamente digitais". O cenário hoje é um pouco diferente do inicialmente previsto em 2000 pelo autor, mas já se vê o impacto das tecnologias de informação e comunicação no acesso à informação, obrigando as bibliotecas a repensarem a oferta de serviços e produtos de informação em ambientes digitais, utilizando novas tecnologias, como as colaborativas da web $2.0 \mathrm{e}$ as novas formas de acesso à rede, como os tablets e smartphones.

\section{Agradecimentos}

A Guilherme Araújo, pelo apoio com a revisão dos dados inicias e a execução de novas análises estatísticas. A Joelma Oliveira e Marina Wille pelo envolvimento e apoio com as etapas iniciais do estudo. 


\section{Referências}

Bell (2007) apud DAGGER, J. Brave new world: reference librarians in the age of Google. Duke Magazine, Sept./Oct., 2008. Disponível em: <http://www.dukemagazine.duke.edu/>. Acesso em: 2 dez. 2008.

BREEDING, M. Preparing for the long-term digital future libraries. Computer in Libraries, v. 31, n.1, p. 24-26, Jan./Feb., 2011. Disponível em: < <http://www.librarytechnology.org/>. Acesso em: 23 mar. 2011.

CAMPOS, M. L. M.; CAMPOS, M. L. de A.; CAMPOS, L. M. Web semântica e a gestão de conteúdos informacionais. In: MARCONDES, C. H. et al. (Orgs.). Bibliotecas digitais: saberes e práticas. 2. ed. Brasília: IBICT, 2006. p. 55-74.

COSTA, M. M. A utilização de ferramentas colaborativas em unidades de informação: web 2.0 em perspectiva. In: CONGRESSO BRASILEIRO DE BIBLIOTECONOMIA E DOCUMENTAÇÃO, 23., 2009, Bonito-MS. Anais... Bonito: FEBAB, 2009. CD-Rom.

O social bookmarking como instrumento de apoio à elaboração de guias de literatura na Internet. 2011. 250f. Dissertação (Mestrado em Ciência da Informação) - Universidade de Brasília, Brasília, 2011.

COORDENAC̄ÃO DE APERFEICCOAMENTO DE PESSOAL DE NÍVEL SUPERIOR (CAPES). Portal de Periódicos da Capes comemora dez anos. 2010. Disponível em <http://www.capes.gov.br/servicos/sala-de-imprensa/36noticias/4200-portal-de-periodicos-da-capes-comemora-dez-anos $>$.

Acesso em: 8 jun. 2011.

CUNHA, M. B. da. Construindo o futuro: a biblioteca universitária em 2010. Ciência da Informação, Brasília, v. 29, n. 1, p. 71-89, jan./abr. 2000.

Das bibliotecas convencionais às bibliotecas digitais: diferenças e convergências. Perspectivas em Ciência a Informação, v. 13, n. 1, p. 217, jan./abr. 2008.

A biblioteca universitária na encruzilhada. DataGramaZero, v. 11, n. 6, dez. 2010. Disponível em: <www.dgz.org.br/>. Acesso em: 10 jun. 2011.

CUNHA, M. B. da; PESSOA, P. Perspectivas do serviço de referência digital. Informação \& Sociedade, João Pessoa, v. 17, n. 3, p. 69-82, set./dez. 2007.

DAGGER, J. Brave new world: reference librarians in the age of Google. Duke Magazine, Sept./Oct., 2008. Disponível em: <http://www.dukemagazine.duke.edu/>. Acesso em: 2 dez. 2008. 
DOUGHERTY, W. C. Virtualization and libraries: the future is now (or virtualization: whiter libraries or libraries wither?). The Journal of Academic Librarianship, v. 35, n. 3, p. 274-276, Mar. 2009.

DUTRA, J. D. O uso do twitter nas bibliotecas brasileiras. 2010. $49 \mathrm{f}$. Monografia (Bacharelado em Biblioteconomia) - Universidade de Brasília, Brasília, 2010.

FARKAS, M. Subject guide 2.0: reinventing resource lists with wikis. American Libraries, v. 38, n. 5, p. 33, May 2007a.

Social software in libraries: building collaboration, communication and community on-line. New Jersey: Information Today, 2007b. 320p.

. Isn't Del.icio.us?: social bookmarking your way to web guides. American Libraries, v. 39, n. 4, p. 32, Apr. 2008.

GIOVINAZZO, R. A. Modelo de aplicação da metodologia Delphi pela Internet: vantagens e ressalvas. Administração On-line, v. 2, n. 2, abr./jun. 2001. Disponível em: $<$ http://www.fecap.br/adm online/art22/renata.htm >. Acesso em: 4 jul.2008.

GOOGLE. Empresa. Disponível em: <http://www.google.com.br/intl/ptBR/about/corporate/company/>. Acesso em: 14 fev. 2010.

HELMER, O. The use of delphi technique in problems of educational innovations. Santa Mônica: Rand Coorporation, 1966.

LUDWIG, L.; STARR, S. Library as a place: results of a delphi study. Journal of Medical Library Association, v. 93, n. 3, p. 315-326, Jul. 2005.

MANESS, J. M. Library 2.0 theory: web 2.0 and implications for libraries. Webology, v. 3, n. 2, 2006. Disponível em <http://www.webology.ir/2006/v2n2/a25.html>. Acesso em: 3 jun. 2011.

ONLINE COMPUTER LIBRARY CENTER OCLC. Análise do cenário da OCLC em 2003: reconhecimento de padrões: resumo executivo do reporte The 2003 Enviromental Scan: patter recognition. Dublin, Ohio: CCLC, 2004.

OLIVEIRA, J. de S. P. de; COSTA, M. M.; WILLE, M. F. de C. O futuro das bibliotecas brasileiras: estudo delphi. Curitiba: [s. n.], 2008. Inédito.

RETHLEFSEN, M. L. Tags help makes libraries del.icio.us. Library Journal, v. 132, n. 15, p. 26-28, Sept. 2007.

SÁFADI, C. M. Q. Delphi: um estudo sobre sua aceitação. In: SEMINÁRIOS EM ADMINISTRAÇÃO, 5., São Paulo, 2001. Anais... São Paulo: FEA-USP, 2001. CD-Rom.

TUROFF, M.; LINSTONE, H. A. The Delphi method. New York: Addison Wesley, 1975. Disponível em: <http://is.njit.edu/pubs/delphibook/>. Acesso em: 10 jul. 2008.

ZINS, C. Classification schemes of information science: twenty-eight scholars map the field. Journal of the American Society for Information Science and Technology, v. 58, n. 5, p. 645-672, 2007. 
As bibliotecas brasileiras em 2018: resultados da técnica de

Maria Murrieta Costa delfos 